\title{
CORRIGENDUM
}

\section{Plerixafor (Mozobil) for stem cell mobilization in patients with multiple myeloma previously treated with lenalidomide}

\author{
INM Micallef ${ }^{1}$, AD Ho${ }^{2}$, LM Klein ${ }^{3}$, S Marulkar ${ }^{4}$, PJ Gandhi ${ }^{4}$, G Calandra ${ }^{5}$ and PA McSweeney ${ }^{6}$ \\ ${ }^{1}$ Division of Hematology, Mayo Clinic, Rochester, MN, USA; ${ }^{2}$ Department of Internal Medicine, Division of Hematology/Oncology, \\ University of Heidelberg, Heidelberg, Germany; ${ }^{3}$ Department of Medicine, Division of Hematology/Oncology, Lutheran General \\ Hospital, Park Ridge, IL, USA; ${ }^{4}$ Genzyme Corporation, Cambridge, MA, USA; ${ }^{5}$ The Commonwealth Medical College, Scranton, \\ PA, USA and ${ }^{6}$ Rocky Mountain Blood and Marrow Transplant Program, Rocky Mountain Cancer Centers, Denver, CO, USA
}

Bone Marrow Transplantation (2011) 46, 1398; doi:10.1038/bmt.2010.303

Correction to: Bone Marrow Transplantation (2011) 46, 350-355; doi:10.1038/bmt.2010.118

Since the publication of this article the authors have noticed that $G$ Calandra was omitted from the list of author names. The correct author list and affiliations are shown above.

The authors apologize for any inconvenience caused. 